\title{
A Transaction Utility Approach for Bidding in Second-Price Auctions
}

\author{
Serdar Sayman ${ }^{a, *} \&$ Yalçın Akçay ${ }^{b}$ \\ ${ }^{a}$ College of Adm. Sciences \& Econ., Koç University, Rumeli Feneri Yolu, Sariyer, Istanbul 34450, Turkey \\ ${ }^{\mathrm{b}}$ Melbourne Business School, The University of Melbourne, 200 Leicester Street, Carlton, Victoria 3053, Australia
}

Available online 19 December 2019

\begin{abstract}
In both the Vickrey and eBay auctions, bidding the reservation price is the optimal strategy within the conventional utility framework. However, in practice, buyers tend to bid less than their reservation prices, and bid multiple times, thus increase their bids, in the course of an auction. In this paper, we show that both underbidding and multiple bidding behaviors can be consistent with utility maximization, if buyer's utility incorporates a transaction utility (reference price dependent) component. Transaction utility is based on the difference between the buyer's reference price and actual price paid; it captures the perceived value of the deal. More specifically, we show that the optimal bid is lower than the reservation price, but higher than the reference price. Furthermore, buyer may re-bid (above the prior optimal level) if the reference price is revised upon observing a higher current price. (C) 2019 Direct Marketing Educational Foundation, Inc. dba Marketing EDGE. All rights reserved.
\end{abstract}

Keywords: Second-price auctions; Reference price; Transaction utility

\section{Introduction}

Auctions became a part of their economic experience for many consumers, thanks to eBay and similar online platforms. eBay has 179 million active buyers globally; it reported a gross merchandise volume of $\$ 95$ billion in 2018 ("eBay Inc. Reports" 2019) - the share of volume through auctions was around 15\% ("eBay Inc. Facts" 2016). eBay uses a variant of the Vickrey auction akin to ascending English auction. Specifically, it is an asynchronous bidding mechanism; buyers can join or increase their bids for an item before the predetermined auction end time. The highest bidder wins but pays the second-highest bid (plus a small increment). eBay uses a proxy bidding system; at any point in time, it discloses the current price as the second-highest bid plus the increment. ${ }^{1}$

\footnotetext{
* Corresponding author.

E-mail addresses: ssayman@ku.edu.tr (S. Sayman), y.akcay@mbs.edu (Y. Akçay).

${ }^{1}$ Correspondingly, a minimum increment above the current price is required for a new bid. eBay uses increments commensurate with current price; e.g. between $\$ 25.00$ to $\$ 99.99$, the increment is $\$ 1.00$.
}

In both the Vickrey and eBay auctions, normatively optimal strategy for a buyer is to bid the reservation price $(R)$. However, empirical evidence suggests that buyers bid less than their $R$ (underbidding), and they may bid multiple times (e.g. Bajari and Hortaçsu 2003; Zeithammer and Adams 2010). In this paper, we propose a transaction utility based framework, which includes both standard (acquisition utility) and reference-dependent (transaction utility) components, to study bidding behavior in second-price auctions. Acquisition utility is about the value of the item to the buyer relative to its price; it is captured by the difference between the buyer's $R$ and paid price $\left(P_{\mathrm{p}}\right)$. On the other hand, transaction utility reflects the perceived value of the "deal" as a result of comparing $P_{\mathrm{p}}$ with a reference price $\left(P_{\mathrm{ref}}\right)$, which is the anticipated or reasonable price for the item. Furthermore, from a behavioral perspective, the mental impact of a "bad-deal" (negative transaction utility when $P_{\mathrm{p}}>P_{\text {ref }}$ ) is larger than the impact of an otherwise equivalent "bargain" (positive transaction utility when $P_{\mathrm{p}}<P_{\text {ref }}$ ) (Thaler 1985). We show that a utility function with standard and referencedependent components (i) leads to bidding less than the reservation price; and (ii) can explain re-bidding upon a higher 
current price. To give a flavor of the intuition, the standard utility component is maximized when $R$ is bid, and the marginal increase reduces to 0 as the bid price gets closer to $R$. On the other hand, as the bid increases from $P_{\text {ref }}$ to $R$, both the probability and the magnitude of the negative transaction utility increase. ${ }^{2}$ Due to these two opposing effects, bidding $R$ is not the best strategy anymore; the buyer should underbid.

To the best of our knowledge, this is the first paper that applies reference-dependent utility to auctions. Our main contribution is that, in the context of a single private-value item auction, we show that underbidding and multiple-bidding behaviors can be consistent with utility maximization without any changes in the true valuation (reservation price). In addition, our analysis yields a few insights regarding bidding behavior, and has implications for online marketplaces.

\section{Background}

We would like to delineate a few relevant bidding patterns first. Underbidding is understood as the buyer bidding less than her/his reservation price. The problem is, though, such an inference cannot be made for an individual's private valuation if she/he bids only once. Multiple or incremental (or revised) bidding can be interpreted as evidence of underbidding - but then, it is possible that buyer's actual valuation might have increased during the auction. It should be noted that multiple bidding is allowed on eBay, but not in the standard Vickrey auction. Sniping refers to bidding just before the auction time ends; it is a special case of late bidding such that the timing is not due to reactive incremental bidding, but premeditated so that the opposing bidders would not have sufficient time to react (bid). It can be argued that sniping is a strategy against opponents who continually raise bids (Roth and Ockenfels 2002). Hence, presence of sniping implies that there is a subset of buyers who underbid.

Prior research offers empirical evidence for underbidding in eBay and Vickrey settings. Zeithammer and Adams (2010) compare bidding behavior in eBay with what could have been observed if buyers were to conform with normative bidding in Vickrey auctions. Data from three product categories are not consistent with a Vickrey abstraction. A proposed alternative model fits the data better; it seems that many buyers bid in a reactive fashion, implying that they bid less than the true (maximum) valuation. Existence of underbidding in Vickrey auctions is another question. Noussair, Robin, and Ruffieux (2004) compare buyers' willingness-to-pay in Vickrey and Becker-DeGroot-Marschak (BDM) mechanisms vis-à-vis valuations. In that study private valuations are induced values (for an undisclosed item) drawn from a distribution and revealed to

\footnotetext{
${ }^{2}$ We assume $P_{\text {ref }}<R$; otherwise, buyer could bid higher than $R$ (see Concluding Remarks for a discussion) - and $R$ should be interpreted as the "intrinsic" value of the item.
}

participants. Authors find underbidding in early trials for both mechanisms, but with repetition bids get close to induced values. Others have found prevalence of bidding above the induced values (Kagel, Harstad, and Levin 1987; Kagel and Levin 1993). ${ }^{3}$

There is empirical evidence for late and multiple bidding as well. Bajari and Hortaçsu (2003) analyze coin auctions data from eBay. They report that about $1 / 3$ of the bids are submitted in the last $1 / 33$ of the auction duration. Furthermore, average bidder submits two bids during the auction. Similarly, Ockenfels and Roth (2006) compare eBay and the now-extinct Amazon auctions (see also Roth and Ockenfels 2002). Amazon had adopted a second-price auction, but the duration was automatically extended if a bid arrived within 10 minutes of the last bid. The authors report that $50 \%$ of eBay antique auctions have their last bid in the final 5 minutes, whereas this figure is merely 3\% in Amazon auctions. A "soft-close" greatly reduces the strategic advantage of sniping, as reflected in these statistics. Moreover, for eBay auctions, although the majority of the buyers bid only once, average number of bids per buyer turned out to be 1.89 .

Several explanations for under- and multiple bidding are proposed in the literature. Firstly, bidding less than true valuations could be considered an error; observed patterns reflect naïve, inexperienced, or irrational behavior (e.g. Wilcox 2000). If a buyer treats eBay auctions as first-price auctions, and interprets the current price as the highest bid, she might raise her bid to maintain the high-bidder status. Secondly, competitive influences may lead to incremental bidding, such that a desire to win rules over maximizing expected payoff (Heyman, Orhun, and Ariely 2004), as in the case of a price war (Roth and Ockenfels 2002). ${ }^{4}$ Thirdly, willingness-to-pay can increase over time due to a (quasi) endowment effect in privatevalue auctions (Heyman, Orhun, and Ariely 2004). Endowment refers to the bidder's partial attachment to the item before the auction is finalized, leading to a change in item valuation. A final argument applies to common-value auctions; here opponents are presumed to have different signals for the expost (common) value of the item (e.g. an oil reserve site). Multiple bidding can arise as the item value is inferred from others' bids (Roth and Ockenfels 2002). We should note that our focus here is private-value auctions. The common theme of the above explanations is that there is no rationale to

\footnotetext{
3 Although bidding higher than the induced value decreases expected payoffs, it increases the chances of "winning" the auction. Subjects may focus on winning (buying) when they consider this as the goal of the experiment, or to prevent opponents from winning (Noussair, Robin, and Ruffieux 2004). Evidently, induced value is not equivalent to reservation price, or maximum willingness-to-pay. We can speculate that absence of a reference price for induced value items may explain why underbidding is less common in such experiments (see below).

${ }^{4}$ Shilling by a dishonest seller could be counted under competitive reasons. Shilling is bidding without a genuine interest in buying but to influence other bidders or to ensure a minimum price level. Shill bidder may be the seller himself / herself or a collaborator.
} 
underbidding (note that the latter two arguments are concerned with an update to (true) valuation, but not with underbidding). In contrast, the current paper proposes an economic intuition for such bidding behavior. ${ }^{5}$

There are a few analytical papers that feature under- and/or multiple bidding as an equilibrium (rational) strategy. In Hossain (2008), one type of buyer does not know her/his exact valuation but can tell whether it is above a posted price. Such an uninformed buyer would bid multiple times until the posted price is above her/his valuation or she/he is the eventual winner. This is not underbidding per se; the buyer bids to uncover her true valuation. In Peters and Severinov (2006), sequentially arriving buyers face multiple auctions; sellers offer one unit of the homogenous good with different reserve prices, and buyers wish to acquire a single unit. Authors focus on the coordination and allocation properties of the design, and show that bidding the true valuation is not a dominant strategy. Our framework, in contrast, considers the quintessential single-unit auction without any consideration of such coordination issues or uncertain valuations.

\section{Modeling Bidding Behavior}

\section{Traditional Approach}

We consider a sealed-bid Vickrey auction for a privatevalue item: the highest bidder wins the item but pays the second highest bid. We use the Vickrey abstraction for comparing the traditional (standard) and transaction utility (provided in "Transaction Utility Approach") approaches. In "Bidding when Current Price Is Observed," we will examine the case where the bidder observes the current price to capture the relevant dynamics in eBay auctions. Our model is a decision theoretical one (refer to Rothkopf and Harstad 1994 for a treatment of such models in auctions; and King and Mercer 1991 for an example).

The focal buyer (bidder) has a reservation price $R$ for the single item on the auction. If the buyer pays $P_{\mathrm{p}}$ for the item, she/he receives a net utility:

$u=R-P_{\mathrm{p}}$

In our model, competition represents the opponent, or the highest bidder among multiple opponents. Competition's bid is uncertain from the focal bidder's perspective. For instance, auctions for antique Japanese sewing boxes end at different prices due to variations in the number of bidders and their valuations and product characteristics. We capture the uncertainty in the competition's bid using a random variable $X$. We

\footnotetext{
5 We choose not to draw on the concept of "rationality". Mental accounting and behavioral decision theory at large are based on the premise that individuals violate normative principles. However, transaction utility theory is a modified version of standard theory, and whether or not it excludes rationality is subjective.
}

assume that $X$ has a probability density function $f(x)$ with support over $[0,1] .^{6}$

Let $P \in[0,1]$ be the bid price by the buyer. Buyer wins if $X$ is less than $P$; and probability of winning is $F(P)$, where $F($. denotes the cumulative distribution of $f($.$) . Accordingly, the$ buyer pays $P_{\mathrm{p}}=X$ if she/he ends up winning the auction. Otherwise, her/his net utility is zero and she/he pays nothing. ${ }^{7}$ Proposition 1 presents the optimal bidding under the traditional utility approach; essentially replicating the standard Vickrey solution. We provide all proofs in the Technical Appendix.

Proposition 1. When there is no transaction utility, optimal bid $P^{*}=R$.

Expected utility from bid $P$ is given by

$\mathrm{E}[u]=F(P) \mathrm{E}[R-X \mid X<P]=\int_{0}^{P}(R-x) f(x) d x$.

We show that $\partial \mathrm{E}[u] / \partial P \geq 0$ as long as $P \leq R$, and so the buyer must bid the reservation price $R$ to maximize expected utility. The intuition is briefly as follows: if the buyer bids $P<R$, she/he forgoes the opportunity of winning the auction and getting positive utility when competition's bid $X \in(P, R)$. In other words, buyer can potentially do better by bidding $P^{*}=R$.

\section{Transaction Utility Approach}

Transaction utility stems from a comparison of paid price with a reference price (Thaler 1985). Reference price is a subjective benchmark used by the buyer; e.g., "fair" price, last price paid etc. For instance, even though a buyer is initially happy with the purchase of a souvenir bought on a tour, she/he could be upset upon learning that others bought the same item at a lower price, which serves as a reference in this case. Reference price may evolve through prior experiences, and can be influenced by external factors such as advertising (see Mazumdar, Raj, and Sinha 2005 for a review of reference price research). Regarding our framework, it is conceivable that $P_{\text {ref }}$ is not independent of $f(x)$. Indeed, $f(x)$ being shaped by buyer's prior experiences is implicit. We specify $P_{\text {ref }}$ as a function of the expected value of $X: P_{\text {ref }}=h\left(\mathrm{E}_{f}[X]\right)$ where $h($.$) is non-$ decreasing. This specification is general in the sense that it allows $P_{\text {ref }}$ to be constant and/or less than the minimum support of $f(x) . P_{\text {ref }}$ is the amount below (above) which the paid price will make the buyer happy (unhappy) beyond the standard

\footnotetext{
${ }^{6}$ We can illustrate how $f(x)$ can be derived from competition's bids with an example. Let $Y_{1}, Y_{2}, \ldots, Y_{n}$ denote independent and identically distributed bids from the competition for the item. The number of bids $n$ itself is uncertain. Then $X=\max \left(Y_{1}, Y_{2}, \ldots, Y_{n}\right)$ for any given $n$. Assume that $Y_{i}, i=1,2, \ldots, n$, is uniformly distributed between 0 and 1 , and $n$ follows a geometric distribution with parameter $\lambda$; i.e., $\mathbb{P}(n=k)=\lambda(1-\lambda)^{k-1}$, where $k \in\{1,2,3, \ldots\}$. Here, $1 / \lambda$ is the expected number of bids from the competition. Using order statistics we obtain: $f(x)=\frac{\lambda}{(1-(1-\lambda) x)^{2}}$ and $\mathrm{E}[X]=\frac{1+\lambda \ln \lambda-\lambda}{(1-\lambda)^{2}}$.

${ }^{7}$ Utility from the outside option is set to 0 without losing any generality; $R$ can be interpreted as the price at which the bidder would switch to the outside option.
} 
utility; this does not necessitate a boundary at the minimum possible bid by competition. $f(x)-P_{\text {ref }}$ relationship will matter in the next section where current price is observable. We assume $0 \leq P_{\text {ref }}<R$.

Transaction utility, as defined by Thaler (1985), distinguishes between positive and negative deviations from the reference price. In particular, a negative deviation has more impact on utility than a comparable positive one. This asymmetry is also called "bad-deal aversion" (e.g. Isoni 2011). For transaction utility, we use a two-piece linear function similar to that in Isoni $(2011)^{8}$ :

$u=\left\{\begin{array}{cl}\left(R-P_{\mathrm{p}}\right)+\alpha\left(P_{\text {ref }}-P_{\mathrm{p}}\right) & \text { if } P_{\mathrm{p}} \leq P_{\text {ref }} \\ \left(R-P_{\mathrm{p}}\right)-\beta\left(P_{\mathrm{p}}-P_{\text {ref }}\right) & \text { if } P_{\mathrm{p}}>P_{\text {ref }}\end{array}\right.$

$\alpha$ and $\beta$ capture the impact of good and bad deals respectively; and $\beta>\alpha>0$.

Total utility is a decreasing function of $P_{\mathrm{p}}$ with a kink at $P_{\mathrm{p}}=P_{\text {ref }}$, where it is equal to the standard utility (see Fig. 1). Note that $P_{\mathrm{p}}$ is the price paid, not the price bid. Bidding higher increases the chances of winning the auction, but also the room for a bad-deal. The question is what bid price represents the best trade - off. It turns out that the optimal bid is less than $R$ :

Proposition 2. When the buyer derives transaction utility, optimal bid $P^{*}=\frac{R+\beta P_{\text {ref }}}{1+\beta}$; where $P_{\text {ref }}<P^{*}<R$.

Let us first explain the intuition for why $P^{*}$ is not less than $P_{\text {ref. When } P} \leq P_{\text {ref }}$, it is for sure that $P_{\mathrm{p}}<P_{\text {ref }}$ (i.e. no baddeals). In this case, first row of (2) applies where $\left(R-P_{\mathrm{p}}\right)$ represents a positive deviation from $R$, and $\alpha\left(P_{\text {ref }}-P_{\mathrm{p}}\right)$ a positive one from $P_{\text {ref. }}$. The solution has the same logic as in the traditional approach in "Traditional Approach." Expected utility E[u] increases with bid $P$ when $P \in\left(0, P_{\text {ref }}\right]$. Thus, bidding $P_{\text {ref }}$ is better than bidding anything less.

We should also explain why $P^{*}$ is less than $R$. When $P>P_{\text {ref }}, P_{\mathrm{p}}$ can be higher or lower than $P_{\text {ref. }}$. Expected utility given $P$ is conditional on competition's bid:

$$
\begin{aligned}
\mathrm{E}[u]= & \int_{0}^{P_{\text {ref }}}\left((R-x)+\alpha\left(P_{\text {ref }}-x\right)\right) f(x) d x \\
& +\int_{P_{\text {ref }}}^{P}\left((R-x)-\beta\left(x-P_{\text {ref }}\right)\right) f(x) d x
\end{aligned}
$$

which can be written as

$$
\begin{aligned}
\mathrm{E}[u]= & \int_{0}^{P}(R-x) f(x) d x+\int_{0}^{P_{\text {ref }}} \alpha\left(P_{\text {ref }}-x\right) f(x) d x \\
& +\int_{P_{\text {ref }}}^{P}-\beta\left(x-P_{\text {ref }}\right) f(x) d x
\end{aligned}
$$

Three terms in the above expression behave differently with increasing $P$ : (i) the first term, (positive) standard utility component, increases with $P$, and it is maximized at $R-$ as in "Traditional Approach." (ii) the second term, which reflects the (positive) good-deal, does not depend on $P$. (iii) the third term

\footnotetext{
${ }^{8}$ Using the kinked non-linear value function $v($.$) (Kahneman and Tversky$ 1979; Thaler 1985) does not change our key results.
}

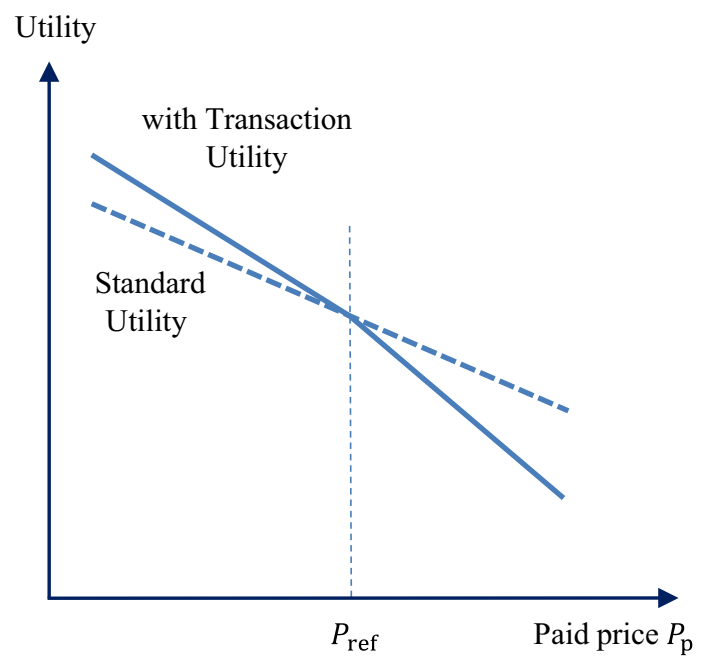

Fig. 1. Transaction versus standard utility.

is the (negative) bad-deal component; it increases in magnitude with $P$. What happens is that (i) cannot offset (iii) beyond a certain point. Hence, the optimal bid $P^{*}<R$.

Optimal bid $P^{*}=\frac{R+\beta P_{\text {ref }}}{1+\beta}$ represents a weighted average of $P_{\text {ref }}$ and $R . P^{*}$ increases with both $P_{\text {ref }}$ and $R$. It is intuitive that as the anticipated trade price or value to the buyer increases, she should bid higher. On the other hand, $P^{*}$ decreases with $\beta$; a higher $\beta$ means stronger aversion to bad-deals, hence she would bid closer to $P_{\text {ref. }}$.

We would like to note that $P^{*}<R$ holds even when $\alpha=0$. In other words, the buyer does not necessarily have to "like" good-deals; as long as she/he "dislikes" bad-deals, she/he would bid less than $R$. The condition $\beta>\alpha>0$ comes from the mental accounting framework of Thaler (1985).

There are two special cases for optimal bidding: (i) The first one is where $P^{*}$ is larger than the maximum possible bid by competition; that is, $f(x)=0$ for all $x>P^{*}$. In that case buyer can bid any $P \in\left[P^{*}, R\right]$. Incidentally, traditional utility approach leads to the same result where $\mathrm{E}[u]$ would be independent of bid $P \in\left[P^{*}, R\right]$ as well. (ii) A second special case is where $P^{*}$ is smaller than the minimum possible $X$; that is, $f(x)=0$ for all $x<P^{*}$ (this means $P_{\text {ref }}$ is less than the minimum support of $X$, because $P_{\text {ref }}<P^{*}$ ). In that case, probability of winning with optimal bid $P^{*}$, and the expected utility $\mathrm{E}[u]$, will be 0 . Consequently, it does not matter whether buyer bids $P^{*}$ or does not bid at all.

\section{Bidding When Current Price Is Observed}

We now examine a variant of second-price auction in which bids are allowed during a specified auction period, and the current price $P_{\mathrm{o}}$ is observable meanwhile, as in eBay auctions. $P_{\mathrm{o}}$ is the second highest bid, or the starting bid when there is only one bid. (We ignore the trivial increment in eBay for practical reasons.) Traditional utility model does not entail a modification for the case of disclosed $P_{\mathrm{o}}$; thus we proceed with the transaction utility model only. We will first specify the bid strategy; then we will look at whether the present framework 
can accommodate revised (incremental) bidding behavior, if multiple bidding is allowed.

Asynchronous nature of competing bids can be visualized in the following manner. Suppose bidders with different valuations arrive randomly following a stochastic process during the auction period. It is conceivable that some bidders actively follow new auctions, so they arrive early; others land via random search or checking, possibly with higher probability towards the end. Furthermore, bids are submitted (or not) after deliberation. The end picture is a distribution of the number and timings of competing bids in the form of increasing current prices. Our interest here is not the specific order of bids, but rather the bidding strategy of a buyer who maintains a transaction utility. We focus on the focal bidder arriving at a particular point in time and observing $P_{\mathrm{o}}$. Whether or not the opponents confirm to transaction utility is not important for our purposes.

An observed $P_{\mathrm{o}}$ means that competition's bid $X \geq P_{\mathrm{o}}$. If there were an a priori $f(x)$, the buyer will update it (not necessarily in the form of a truncation because $P_{\mathrm{o}}$ can be less than the minimum support of subjective $f(x)$ ). Alternatively, she may form the distribution after seeing $P_{\mathrm{o}}$ in the first place. For generality purpose, we designate the pdf after observing $P_{\mathrm{o}}$ (just before placing the bid) with $f_{\mathrm{o}}(x)$, to distinguish it from $f$ $(x)$. Correspondingly, $P_{\text {ref. o }}=h\left(\mathrm{E}_{f_{0}}[X]\right.$ is based on $f_{\mathrm{o}}(x)$. Note that $f_{\mathrm{o}}(x)=0$ for $x<P_{\mathrm{o}}$, but it is possible to have $P_{\text {ref. o }}<P_{\mathrm{o}}$. Optimal bidding reflects a control-limit rule:

Proposition 3. When current price $P_{\mathrm{o}}$ is available, optimal bid strategy is:

$$
\left\{\begin{array}{l}
\operatorname{bid} P_{1}^{*}=\frac{R+\beta P_{\text {ref.o }}}{1+\beta} \text { if } P_{1}^{*}>P_{\mathrm{o}} \\
\text { no bids, } \quad \text { otherwise }
\end{array}\right.
$$

For the case of $P_{1}^{*}>P_{\mathrm{o}}$, the intuition is similar to Transction Utility Approach, except that (in case the auction is won) price paid $P_{\mathrm{p}}>P_{\mathrm{o}}$. (i) If the reference price $P_{\text {ref. o }}>P_{\mathrm{o}}$, both good and bad-deals are likely. (ii) If $P_{\text {ref. o }}<P_{\mathrm{o}}$, it is for sure that the buyer will incur a bad-deal by bidding $P_{1}^{*}$; but $P_{1}^{*}$ still represents the best trade-off between the bad-deal versus the standard utility. The larger the difference between $P_{\text {ref. o }}$ and $P_{\mathrm{o}}$, the smaller $\beta$ should be, to satisfy $P_{1}^{*}>P_{\mathrm{o}}$.

For the case of $P_{1}^{*}<P_{\mathrm{o}}$, bidding $P_{\mathrm{o}}+\varepsilon$ may be a possibility, if this yields a positive utility, albeit less than optimal (note that bidding less than $P_{\mathrm{o}}$ is not allowed). However, $\mathrm{E}[u]<0$ for any bid $P>P_{\mathrm{o}}>P_{1}^{*}$. The intuition is as follows: if $P>P_{\mathrm{o}}$ is bid and auction is won, price paid $P_{\mathrm{p}}$ will be substantially higher than $P_{\text {ref. o. }}$. Expected bad-deal cannot be compensated by the standard component of the utility in that case, and overall utility will be negative. So, the best strategy is not to bid when $P_{1}^{*}<P_{\mathrm{o}}$.

Multiple bidding. Control-limit rule based bidding strategy applies to any current price and the reference price then. A special case is where the buyer observes a higher current price $P_{\mathrm{o}}{ }^{\prime}$ after having bid $P_{1}^{*}>P_{\mathrm{o}}$ earlier. As per the auction mechanism, $P_{\mathrm{o}}^{\prime} \geq P_{1}^{*}$ (equality applies if $P_{1}^{*}$ is the second highest bid at the moment). We are interested in the possibility of a revised optimal bid $P_{2}^{*}$ such that $P_{2}^{*}>P_{\mathrm{o}}{ }^{\prime} \geq P_{1}^{*}$.

In the current analysis, competition represents the highest bidding opponent; it is an omnibus entity. A new current price could be on the account of a newly arrived opponent or one that had also bid previously. How does a(ny) bidder come about seeing a revised current price $P_{\mathrm{o}}{ }^{\prime}$ (i.e., "arrive" again)? First, bidders can check out the progress of participated auctions on eBay. They can also be notified by eBay when outbid or auction end is near. In addition, if the submitted bid is less than the current highest bid (but of course higher than $P_{\mathrm{o}}$ ), $P_{\mathrm{o}}{ }^{\prime}$ is observed right after $P_{\mathrm{o}}$, in which case $P_{\mathrm{o}}{ }^{\prime}$ would be equal to the submitted bid.

Optimal bid would not change unless a parameter in Proposition 3 is updated. Here we will study the case for the reference price, as it is internal to the current framework (below we will discuss another possibility). When a new $P_{\mathrm{o}}^{\prime} \geq P_{1}^{*}$ is observed, prior $f_{\mathrm{o}}(x)$ is not valid anymore; if the updated distribution $f_{\mathrm{o}}{ }^{\prime}(x)$ leads to a sufficiently high new reference price $P_{\text {ref. o }}$, the buyer would re-bid. For instance, for the truncated distribution $f_{\mathrm{o}}{ }^{\prime}(x)=f_{\mathrm{o}}\left(x \mid X>P_{\mathrm{o}}{ }^{\prime}\right)$, it is evident that $\mathrm{E}_{f_{0}^{\prime}}[X] \geq \mathrm{E}_{f_{0}}[X]$. As the mapping function $h($.$) is non-decreas-$ ing, corresponding $P_{\text {ref. o' }} \geq P_{\text {ref. o. }}$.

Proposition 4. There exist a $P_{\text {ref. o' }} \geq P_{\text {ref. o }}$ such that when $P_{\mathrm{o}}^{\prime}>P_{1}^{*}$, a new optimal bid $P_{2}^{*}>P_{\mathrm{o}}^{\prime}$ exists.

More specifically, if $P_{\text {ref.o }}^{\prime}>\frac{P_{0}^{\prime}(1+\beta)-R}{\beta}>P_{\text {ref.o }}$, the buyer's new optimal bid $P_{2}^{*}$ would be higher than $P_{\mathrm{o}}{ }^{\prime}$. Note that reservation price $R$ does not change ${ }^{9}$; only the reference above which the buyer gets disutility from a bad-deal is raised. If the reference price does not increase sufficiently (or does not change at all), the buyer would not re-bid. Along the same line, there would be a maximum price beyond which the buyer will "let go" of the item. The function $h($.) being less steep/flat in the relevant range means that the reference price is not affected by current bids; it is relatively stable.

A general case of reference-dependence. Our account of multiple bidding is based on updating the reference price due to increased competing bid. A more general reference-dependent utility can incorporate reference effects on the item (ownership) dimension of the transaction, in addition to the price (e.g. Köszegi and Rabin 2006). Such an approach can accommodate multiple bidding even when $P_{\text {ref }}$ is not increased. In particular, a negative deviation (loss) in the item dimension might compel the buyer to increase her bid in the following manner. A high bidder may come to expect to own the item, develop a partial attachment, and experience a feeling of loss if auction is not won. Heyman, Orhun, and Ariely (2004) use the term quasiendowment to (qualitatively) describe this partial attachment. Applying this notion to the current framework, upon bidding $P$, buyer can now expect to own the item in a probabilistic sense, with a reference utility of $\omega(P) \times R$ where $\omega($.) is nondecreasing. Later when a higher price $P_{\mathrm{o}}{ }^{\prime}>P$ is observed,

\footnotetext{
${ }^{9}$ Updating $R$ would not be commensurate with a private-value auction setting.
} 
not obtaining the item should feel as a loss of $\beta_{i} \omega(P) \times R$ where $\beta_{i}$ is the impact of loss. ${ }^{10}$ At that point, loss of money by bidding higher than $P_{\mathrm{o}}{ }^{\prime}$ (see above) could be deemed more favorable compared to the loss from the item dimension. That is, buyer will re-bid in order not to experience the negative transaction utility on the item dimension.

\section{Concluding Remarks}

In this paper we apply the transaction utility approach to second-price auctions; such a model can predict underbidding (in Vickrey and eBay auctions) and multiple bidding (in eBay) behaviors. More specifically, our analysis indicates that a buyer would bid less than her/his reservation price (Proposition 2), if the utility function incorporates response to good- versus bad-deals, which represent deviations from a reference price. Furthermore, the buyer may re-bid over a current price, which is higher than her/his previous bid, if the reference price is increased sufficiently (Proposition 4). While reference price depends on the distribution of likely bids by competition in our framework, the former result applies irrespective of how it is formed. In addition, a more general reference-dependent utility (that involves references on both price and item dimensions) can also accommodate multiple bidding, along the line of a quasi-endowment explanation.

A relevant aspect of multiple/revised bidding is consistency or rational expectations. Köszegi and Rabin (2006) examine the case of reference point as endogenous expectations, and assume that these expectations are consistent with optimal behavior given the expectations (referred to as rational expectations or personal equilibrium). Such an approach would predict that the buyer would consider her/his response to observing a higher current price to begin with - and would have chosen the initial bid accordingly. Hence, revised bidding does not comply with personal equilibrium.

Our analysis lends itself to a few interesting insights. A first and essential one is that bids in second-price auctions should be between $P_{\text {ref }}$ and $R$. In a similar vein, in experimental settings where high versus low $P_{\text {ref }}$ is manipulated, buyers with high $P_{\text {ref }}$ should have higher bids. Secondly, average bids upon observing $P_{\mathrm{o}}$ should be higher for buyers who had bid earlier than those who had not. ${ }^{11}$ This argument is in line with Heyman, Orhun, and Ariely (2004); and they already provide some empirical support. In a survey based study, bids from two groups are compared: (i) one group of subjects were the leading bidders at first, and later observed that they were no longer the highest bidder; (ii) the second group simply observed that others had bid. Average bids in (i) were higher than bids in (ii). In a second study with real money auctions, Heyman, Orhun, and Ariely (2004) look at the effect of the number of periods that the subject is allowed to bid (to capture the length of quasiownership duration); final bid is higher in the longer duration condition. A third insight can be derived by relaxing an assumption; if we let $P_{\text {ref }}$ to be larger than $R$, we see that the

\footnotetext{
${ }^{10}$ Revision of the reference to "not winning the item" will not be instant (or will be partial). There is evidence that it takes more time to adapt to negative changes than to positive ones (Arkes et al. 2008).

11 This should exclude the sniping behavior.
}

buyer will bid higher than $R$. The intuition is as follows; utility will include one component maximized at $R$ and another at $P_{\text {ref }}>R$; so the overall maximum should be at a bid higher than $R$. In this case, $R$ should better be interpreted as the "intrinsic" value of the item, rather than the maximum willingness-to-pay.

Our work also has implications for interactive marketing. From a seller's point of view, bidding less than $R$ is not desirable. The seller may benefit if transaction-utility is de-emphasized compared to acquisition/consumption utility. Uncertainty surrounding $P_{\text {ref }}$ might help in that regard; highlighting unique aspects of the item, if applicable, could make it difficult for the bidder to set a reference price (and on top could increase $R$ ). The seller could also suggest that buyers should better bid according to how much they like/value the item; not according to the current price, which will possibly increase. For instance, one eBay seller writes "now that you have found exactly what you have been looking for"; an excellent way of emphasizing the uniqueness of the item and the bidder's liking. To buyers, eBay advises placing the "highest bid" in the closing seconds. There are two issues here. First, "highest bid" is not necessarily static. Bidders, including snipers, should better leave enough time at the very end, in case they would like to update their bid. Many buyers have experienced regret for not checking the progress and updating their bid before the auction's end. Secondly, "highest bid" should be explained in a practical manner; we suggest the following: the maximum amount you are prepared to pay and still be happy to have won the item. Respective bidding behavior should benefit both the seller and the buyer.

To the best of our knowledge, this is the first application of transaction-utility, or more generally reference-dependent utility, to second-price auctions. Implications of the analysis are consistent with some patterns in the bidding behavior reported in literature. We believe that future theoretical or empirical auction/bidding models can benefit from incorporating such a transaction-utility approach.

\section{Technical Appendix}

\section{Proof of Proposition 1}

Expected utility $\mathrm{E}[u]=F(P) \times \mathrm{E}[R-X \mid X<P]+(1-F$ $(P)) \times 0$

$=F(P) \frac{\int_{0}^{P}(R-x) f(x) d x}{F(P)}=\int_{0}^{P}(R-x) f(x) d x$

Using Leibniz rule, $\frac{\partial \mathrm{E}[u]}{\partial P}=(R-P) f(P) \geq 0$ for $P \leq R$. Expected utility is maximized at $P^{*}=R$.

\section{Proof of Proposition 2}

Eq. (2) can be written as,

$$
u= \begin{cases}\left(R+\alpha P_{\text {ref }}\right)-(1+\alpha) P_{\mathrm{p}} & \text { if } P_{\mathrm{p}} \leq P_{\text {ref }} \\ \left(R+\beta P_{\text {ref }}\right)-(1+\beta) P_{\mathrm{p}} & \text { if } P_{\mathrm{p}}>P_{\text {ref }}\end{cases}
$$


- Case 1: $P \leq P_{\text {ref }}$

It is for sure that $P_{\mathrm{p}} \leq P_{\text {ref. }}$ The first line of (A1) can be considered as a revision of the standard utility in (1), where the reservation price is $R^{\prime}=R+\alpha P_{\text {ref }}$ and price paid is $P_{\mathrm{p}}{ }^{\prime}=$ $(1+\alpha) P_{\mathrm{p}}$.

Correspondingly, $\frac{\partial \mathrm{E}[u]}{\partial P} \geq 0$ for $P \leq R+\alpha P_{\text {ref. Thus, } E[u] \text { is }}$ maximized at the corner $P=P_{\text {ref. }}$.

- Case 2: $P>P_{\text {ref }}$

In this case competition's bid (price paid $P_{\mathrm{p}}$ ) can be lower or higher than $P_{\text {ref. }}$

$$
\begin{aligned}
& E[u]= \int_{0}^{P_{\text {ref }}}\left(\left(R+\alpha P_{\text {ref }}\right)-(1+\alpha) x\right) f(x) d x \\
&+\int_{P_{\text {ref }}}^{P}\left(\left(R+\beta P_{\text {ref }}\right)-(1+\beta) x\right) f(x) d x \\
& \frac{\partial \mathrm{E}[u]}{\partial P}>0 \text { for } P<\frac{R+\beta P_{\text {ref }}}{1+\beta} \text { and } \frac{\partial \mathrm{E}[u]}{\partial P}<0 \text { for } P>\frac{R+\beta P_{\text {ref }}}{1+\beta} .
\end{aligned}
$$

It is straightforward to show that $P_{\text {ref }}<\frac{R+\beta P_{\text {ref }}}{1+\beta}<R$.

As E $[u]$ maximized at $P=P_{\text {ref }}$ in Case 1 , global maximum should be from Case 2: $P^{*}=\frac{R+\beta P_{\text {ref }}}{1+\beta}<R$.

\section{Proof of Proposition 3}

The following is based on $f_{\mathrm{o}}(x)$ and the corresponding $P_{\text {ref. o, }}$ where $f_{\mathrm{o}}(x)=0$ for $x<P_{\mathrm{o}}$

- Case (i): $P_{\mathrm{o}} \leq P_{\text {ref. o }}$

As in Proposition 2, optimal bid $P_{1}^{*}=\frac{R+\beta P_{\text {ref.o }}}{1+\beta}>P_{\mathrm{o}}$.

- Case (ii): $P_{\text {ref. o }}<P_{\mathrm{o}}<P_{1}^{*}$

In this case, buyer will definitely incur a bad-deal:

$E[u]=\int_{P_{\mathrm{o}}}^{P}\left(\left(R+\beta P_{\text {ref.o }}\right)-(1+\beta) x\right) f_{\mathrm{o}}(x) d x$

$\frac{\partial \mathrm{E}[u]}{\partial P}=\left[\left(R+\beta P_{\text {ref.o }}\right)-(1+\beta) P\right] f_{\mathrm{o}}(P)$

$\frac{\partial \mathrm{E}[u]}{\partial P}=0$ will be satisfied at $P_{1}^{*}=\frac{R+\beta P_{\text {ref.o }}}{1+\beta}$.

It is straightforward to show that $\left(R+\beta P_{\text {ref. o }}\right)-(1+\beta)$ $x>0$ when $x<P_{1}^{*}$; thus $\mathrm{E}[u]>0$ at $P=P_{1}^{*}$.

Therefore, $P_{1}^{*}$ is the optimal bid.

- Case (iii): $P_{1}^{*}<P_{\mathrm{o}}$ $E[u]=\int_{P_{\mathrm{o}}}^{P}\left(\left(R+\beta P_{\text {ref.o }}\right)-(1+\beta) x\right) f_{\mathrm{o}}(x) d x$ $\frac{\partial \mathrm{E}[u]}{\partial P}<0$ for $P>P_{1}^{*}$, buyer would consider bidding $P_{\mathrm{o}}$ plus a minimal increase.

However, $\left(R+\beta P_{\text {ref. o }}\right)-(1+\beta) x<0$ when $x>P_{1}^{*}$.

In other words, $\mathrm{E}[u]<0$ for any feasible bid $P>P_{\mathrm{o}}>P_{1}^{*}$. Therefore, buyer should not bid at all.

\section{Proof of Proposition 4}

It is straightforward to show that the new optimal bid $P_{2}^{*}=\frac{R+\beta P_{\text {ref.o }}^{\prime}}{1+\beta}>P_{\text {o }}^{\prime}$ if $P_{\text {ref.o }}^{\prime}>\frac{P_{\mathrm{o}}^{\prime}(1+\beta)-R}{\beta}$. Furthermore, $P_{\text {ref. o }}>$ $P_{\text {ref. o }}$ because $P_{\mathrm{o}}{ }^{\prime}>P_{1}^{*}>P_{\text {ref. o. }}$.

\section{References}

Arkes, Hal R., David Hirshleifer, Danling Jiang, and Sonya Lim (2008), "Reference Point Adaptation: Tests in the Domain of Security Trading," Organizational Behavior and Human Decision Processes, 105, 1, 67-81.

Bajari, Patrick and Ali Hortaçsu (2003), "The Winner's Curse, Reserve Prices, and Endogenous Entry: Empirical Insights from eBay Auctions," The Rand Journal of Economics, 34, 2, 329-55.

eBay Inc (2016), "Fact Sheet Retrieved from," https://static.ebayinc.com/static/ assets/Uploads/PressRoom/eBay-Q22016FactSheet-Investor-Site.pdf.

(2019), "Reports Fourth Quarter and Full Year 2018 Results," January 29, Retrieved from https://www.ebayinc.com/stories/news/ebay-q4-2018results.

Heyman, James E., Yesim Orhun, and Dan Ariely (2004), "Auction Fever: The Effect of Opponents and Quasi-Endowment on Product Valuations," Journal of Interactive Marketing, 18, 4, 7-21.

Hossain, Tanjim (2008), "Learning by Bidding," The Rand Journal of Economics, 39, 2, 509-29.

Isoni, Andrea (2011), "The Willingness-to-Accept/Willingness-to-Pay Disparity in Repeated Markets: Loss Aversion or 'Bad-Deal' Aversion?" Theory and Decision, 71, 3, 409-30.

Kagel, John H., Ronald M. Harstad, and Dan Levin (1987), "Information Impact and Allocation Rules in Auctions with Affiliated Private Values: A Laboratory Study," Econometrica, 55, 6, 1275-304.

_ and Dan Levin (1993), "Independent Private Value Auctions: Bidder Behaviour in First-, Second-and Third-Price Auctions with Varying Numbers of Bidders," The Economic Journal, 103, 419, 868-79.

Kahneman, Daniel and Amos Tversky (1979), "Prospect Theory: An Analysis of Decision Under Risk," Econometrica, 47, 2, 263-91.

King, Malcolm and Alan Mercer (1991), "Distributions in Competitive Bidding," Journal of the Operational Research Society, 42, 2, 151-5.

Köszegi, Botond and Matthew Rabin (2006), "A Model of ReferenceDependent Preferences," The Quarterly Journal of Economics, 121, 4, 1133-65.

Mazumdar, Tridib, S.P. Raj, and Indrajit Sinha (2005), "Reference Price Research: Review and Propositions," Journal of Marketing, 69, 4, 84-102.

Noussair, Charles, Stephane Robin, and Bernard Ruffieux (2004), "Revealing Consumers' Willingness-to-Pay: A Comparison of the BDM Mechanism and the Vickrey Auction," Journal of Economic Psychology, 25, 6, 725-41.

Ockenfels, Axel and Alvin E. Roth (2006), "Late and Multiple Bidding in Second Price Internet Auctions: Theory and Evidence Concerning Different Rules for Ending an Auction," Games and Economic Behavior, 55, 2, 297-320.

Peters, Michael and Sergei Severinov (2006), "Internet Auctions with Many Traders," Journal of Economic Theory, 130, 1, 220-45.

Roth, Alvin E. and Axel Ockenfels (2002), "Last-Minute Bidding and the Rules for Ending Second-Price Auctions: Evidence from eBay and Amazon Auctions on the Internet," The American Economic Review, 92, 4, 1093-103. 
Rothkopf, Michael H. and Ronald M. Harstad (1994), "Modeling Competitive Bidding: A Critical Essay," Management Science, 40, 3, 364-84.

Thaler, Richard (1985), "Mental Accounting and Consumer Choice," Marketing Science, 4, 3, 199-214.
Wilcox, Ronald T. (2000), "Experts and Amateurs: The Role of Experience in Internet Auctions," Marketing Letters, 11, 4, 363-74.

Zeithammer, Robert and Christopher Adams (2010), "The Sealed-Bid Abstraction in Online Auctions," Marketing Science, 29, 6, 964-87. 